\title{
DOES TRANS RECTAL ULTRASOUND (TRUS) HELPS IN DIFFERENTIAL DIAGNOSIS OF PROSTATE LESIONS? A STUDY AT TERTIARY CARE CENTER.
}

\section{Dr. Dhagash Patel}

\begin{tabular}{ll}
\hline Dr. Brijesh Modh* & ${ }^{*}$ Corresponding Author \\
\hline Dr. Kalpesh & \\
Bhabhor &
\end{tabular}

ABSTRACT BACKGROUND: There are successions of investigations used in evaluation of prostatic pathology Currently digital rectal examination \& serum PSA levels are used for screening of prostatic cancer. Many conventional imaging techniques like plain radiography, computed tomography, radionuclide scintigraphy and transabdominal sonography were proved to be ineffective in detection of many prostatic conditions specially cancer at an early stage. Transrectal ultrasound (TRUS) has traditionally been considered as the pivotal imaging test for the prostate, providing clinically important information regarding benign and malignant conditions. OBJECTIVES: to evaluate the TRUS and colour Doppler findings in various benign and malignant prostatic lesions with respect to its site, echo pattern, capsular status, local invasion, vascularity and to correlate with other investigations, like digital rectal examination and serum PSA etc. and also to study the accuracy of TRUS in differentiating benign from malignant lesions. METHODOLOGY: A prospective observational study carried out over a period of 1.5 years at a tertiary care hospital. All male patient referred to department of radio diagnosis with prostate related complains referred from surgery department. Study includes clinical symptoms, family and personal history, laboratory examination like PSA, radiological examination, digital rectal examination. . Various statistical characteristics of the test such as sensitivity, specificity, positive predictive value, negative predictive value were calculated whenever applicable. OBSERVATIONS: Out of total 64 patients' recruited commonest age group was $61-70$ years $(39.1 \%)$. Commonest prostatic pathology encountered was BPH (56.2\%) followed by prostatic carcinoma (31.3\%), prostatitis (4.7\%), prostatic abscess \& calculus $(3.1 \%)$ prostatic cyst $(1.6 \%)$. $75 \%$ patients of prostatic carcinoma and $13.9 \%$ of Benign Prostate Hypertrophy show PSA value greater than 10ng/ml. Echotexture pattern found on TRUS, in prostatic carcinoma patients was hypoechoic echotexture in $70 \%$ patients followed by mixed echotexture in $20 \%$ patients. Examination in Color Doppler found, $80 \%$ patients of prostatic carcinoma show increased vascularity and $25 \%$ of benign lesion also shows increased vascularity including all three cases of prostatitis and one out of two case of prostatic abscess. CONCLUSION: Any single test alone is not helpful in arriving at a diagnosis, but all the three tests i.e. PSA level, digital rectal examination, and transrectal ultrasound, together give very confirmatory result, specifically to differentiate benign from malignant condition of prostate. . Considering that the initial screening of patients will help in reducing the number of negative biopsies (unnecessary), without impairing the cancer detection capacity.

\section{KEYWORDS : Trans Rectal Ultrasound (TRUS), Prostate Carcinoma, Benign Prostate Carcinoma}

\section{INTRODUCTION}

Prostate pathologies are very common in clinical practice and are associated with increased morbidity and mortality in older men. The pathologies include benign prostatic hyperplasia $(\mathrm{BPH})$, prostatic carcinoma, infectious diseases like prostatitis and other rare disorders like prostatic cyst and calcification. It can lead to various symptoms of urinary tract obstruction and consequently severe impairment of urine flow. These pathologies press the prostatic urethra resulting in urine retention leading to dilatation ureter and hydronepherosis. $[1,2]$

There are successions of investigations used in evaluation of prostatic pathology, among them only few were stood the test of confidence. Many conventional imaging techniques like plain radiography, computed tomography, radionuclide scintigraphy and transabdominal sonography were proved to be ineffective in detection of many prostatic conditions specially cancer at an early stage. Despite earlier claims, to the contrary, MR imaging was also not proved to be effective in accurately differentiating prostatic cancer from benign conditions. [3]

Ultrasound Examination is a widely used and well-tolerated imaging modality for evaluation of the prostate. Recent technical advances in US applications have led to new aspects in the analysis of the prostate. Structural analysis is applied for measurement of prostate volume, study of echo texture, and illustration of tissue stiffness or elasticity. Functional analysis illustrates macro vascularity and micro vascularity.
A trans-rectal ultrasound (TRUS) may also be called prostate sonogram or endorectal ultrasound. It is used to look at the prostate and tissue surrounding prostate. Transrectal ultrasound (TRUS) has traditionally been considered as the pivotal imaging test for the prostate, providing clinically important information regarding benign and malignant conditions including Benign Prostatic Hyperplasia (BPH), prostatitis, prostatic abscess, prostatic cyst and prostate cancer. The TRUS guided systematic prostate biopsy is the Gold standard for diagnosis of prostate cancer. [4] TRUS, also enables visualization of suspected lesions. With improved technology in ultrasound equipment designed for transrectal use, high resolution images of prostate can be obtained on a regular basis.

Currently digital rectal examination \& serum PSA levels are used for screening of prostatic cancer, while transrectal ultrasound and MRI are used for diagnosis of different prostatic conditions, to know the extent of carcinoma and to guide prostatic biopsy. However there is a lack of specificity for PSA value, because PSA more than $4 \mathrm{ng} / \mathrm{ml}$ can imply the presence of prostate cancer, patients with $\mathrm{BPH}$ and inflammatory prostate disorders can also present with increased serum PSA levels. Hence, there is a need for an alternate, cost effective and efficient modality for screening, detection, and differentiation of prostate diseases.

Transrectal ultrasound has received increasing attention recently because of its potential for early detection of prostate cancer. It provides greater detail of zonal anatomy of prostate 
\& echo pattern of the gland and its various lesions. Posterior portion of the gland is better delineated where most of prostate carcinoma arises.

According to some study, men with suspicious lesions depicted on TRUS had a higher risk of being diagnosed with prostate carcinoma. [5] However Ultrasound (US) criteria used to identify and characterize suspicious lesions for diagnosing a malignancy are controversial and have not been well defined. Although increased cancer detection has been reported for the use of colour Doppler US.

It has been reported that prostate cancer tends to have an increased blood flow and therefore may be identified as a lesion of high flow signals on Colour Doppler US. Research has concentrated on the integration of TRUS findings with digital rectal examination (DRE) and PSA levels together with use of newer techniques such as Colour Doppler, and ultrasound with contrast agents for establishing the diagnosis of prostatic disorders along with histopathological correlation.

So, our study was an effort at establishing the role of transrectal ultrasonography in evaluation of prostatic pathology as compared with other investigations like digital rectal examination, serum PSA, and histopathological finding; and its role in differentiating benign and malignant prostatic diseases. Also, to evaluate the TRUS and colour Doppler findings in various benign and malignant prostatic lesions with respect to its site, echo pattern, capsular status, local invasion, vascularity and to correlate with other investigations, like digital rectal examination and serum PSA.

\section{METHODOLOGY}

It was a prospective observational study carried out by the department of Radio diagnosis of a tertiary care hospital. Study was carried out over a period of 1.5 years from July 2015 to December 2016. Approval for the study was obtained from the Human Research ethical committee of the institution before the commencement of the study. Participants were recruited in the study, matching the inclusion criteria and those within the exclusion criteria and not affirming to the consent or procedural guidelines were eliminated out of the study.

\section{INCLUSION CRITERIA}

- All male patients with clinical and digital rectal examination suggestive of prostatic diseases.

- Male patient, who has come for screening and found to have prostate lesion.

- Patients with suspected prostate disease.

\section{EXCLUSION CRITERIA}

- Patients having contraindications for transrectal evaluation.

- Patient who gave negative consent.

All male patient referred to department of radio diagnosis with prostate related complains referred from surgery O.P.D. \& ward of our institute to our department for ultrasound abdomen and pelvis for their abdominal complains and lower urinary tract complain and transrectal sonography for evaluation of prostatic gland disease during the study period were screened for recruitment in the study. Informed written consent was taken after persuading the participants about the possible benefits and implications of the study.

This was a correlative type prospective observational study aimed at calculating sensitivity and specificity of Transrectal Ultrasound (TRUS) in diagnosing prostatic pathology and compare TRUS finding with DRE, PSA, histo-patho finding and other investigations.

Data was collected using pretested and pre-validated questionnaire. Study includes clinical symptoms, family and personal history, laboratory examination like PSA, radiological examination, digital rectal examination. A detailed history was taken like symptoms of prostatism like frequency of micturition, difficulty in micturition, retention of urine, haematuria, infertility, and symptoms of distant metastasis like bone pain, abdominal pain.

Patients were explained the procedure in detail and taken in confidence. Prior to the TRUS examination, patients were told to utilize a fleet enema or laxative for rectal cleansing one hour before the examination. Patient was advised to be in left lateral decubitus position with knees flexed. After performing digital rectal examination (DRE) to ensure no rectal abnormalities TRUS was done using GE RIC5-9D endocavitory microconvex ultrasound probe and $\mathrm{ECl} 23$ microconvex array ultrasound probe with 5-10 MHz frequency on GE Volusion S8 and ESAOTE MY LAB 60 machine respectively, which was wrapped in a sheath. To ensure acoustic contact the sheath contained ultrasound gel. The sheath coated with gel for adequate lubrication, were inserted into the rectum.

Ultrasound examination was initiated in B mode in grey scale on the whole prostatic gland and seminal vesicles, performing the scanning in sagittal and orthogonal planes to assess the presence of any focal lesions and their echo-pattern, compressibility, capsular integrity, extension of the disease process outside the limits of the gland margin. At this moment also the prostate weight was estimated by multiplication of the three dimensions of the gland.

After scanning in grey scale, the colour Doppler was performed, with the colour box adjusted for covering the whole peripheral zone, neurovascular bundles and the greatest part of the internal gland aiming at allowing comparison of vascularization standard between both lobes. If any abnormal vascularization area was found at colour Doppler, the colour box was reduced to increase sensitivity, allowing a better evaluation of the focal change. The colour Doppler gain was set just below the threshold for noise. Low velocity and high sensitivity parameters were utilized. The filters were adjusted to optimize the visualization of low flow and small vessels. Findings at colour Doppler were divided into asymmetry in vascularization (associated or not with focal lesion seen in grey scale) and focal or diffuse increase in vascularity in the peripheral zone. PSA measures were performed previously to the biopsies, using a polyclonal kit by means of the chemiluminescence method, the values $<4.00$ $\mathrm{ng} / \mathrm{ml}$ being considered as normal. TRUS findings were correlated with the biopsy or histopathological examination of the prostate specimen. Image 2 and 3 illustrates prostatic biopsy needle in the parenchyma and echogenic track post biopsy. (Figure $2 \& 3$ )

For calculating sensitivity and specificity one has defined as true-positive cases those cases presenting suspect findings at ultrasound and histopathologically positive for cancer; truenegative cases, in the absence of suspected findings at ultrasound and benign finding at pathology; false-positive, those with suspect findings at ultrasound and benign findings at pathology; and false-negative, those with no suspect finding at ultrasound, but histopathologically diagnosed as cancer.

Confidentiality: Strict confidentiality of their personal details and information related to the study was be maintained at all levels. Name of patient was not appeared on ultrasound images or in study description.

Statistical Analysis: Entry of all data collected from the patients included within the present study was done in 
Microsoft excel. Data analysis would be done by appropriate statistical tests. Descriptive analysis, comparison would be applied. Various statistical characteristics of the test such as sensitivity, specificity, positive predictive value, negative predictive value were calculated whenever applicable. Data was classified accordingly and frequencies were described in number and their respective percentage.

\section{Potential risk and benefits:}

As Ultrasonography is a safe and non-invasive procedure there is and there was no radiation exposure so no risk but transrectal sonography is painful sometimes \& rarely cause tear in perineal region. It is beneficial to the patients by accurate diagnosis of gross disease process with assessment of the involvement and condition of prostatic gland so that treatment can be planned accordingly.

\section{RESULTS}

Over a period of one and half year total 64 patients could be recruited according to inclusion and exclusion criteria of the study. Different parameters of patients like age, presenting clinical finding and other investigations were stratified. Type of lesion, abnormal TRUS finding, location of lesions, pattern of vascularity, echoexture of prostate, capsular status, surrounding structures and calcification were also tabled and evaluated. Final diagnoses of all participants were obtained after histopathology examination of biopsy or surgically resected specimen, on operation and through aspiration.

Most common age group was $61-70$ years (39.1\%), followed by the $71-80$ years of age $(29.7 \%)$ and $51-60$ years of age (18.7\%). Very few patients $(9.4 \%)$ were less than fifty years age. Commonest prostatic pathology encountered in present study was BPH in $56.2 \%$ patients followed by prostatic carcinoma in $31.3 \%$ patients. Next in order of frequency were prostatitis $4.7 \%$, prostatic abscess \& calculus in $3.1 \%$ patients and prostatic cyst in $1.6 \%$. Age wise distribution shows that most common age group for BPH was seventh decade (60\%), followed by sixth (25\%) and eighth (19.4\%) decades. While among all patients with carcinoma, most common were in eighth decade $(60 \%)$, followed by seventh (25\%) and ninth (10\%) decade. Other benign lesions like prostatitis, abscess, calculus and cyst mostly found in patients below seventh decade. (Table 1)

The common presenting symptom was lower urinary tract symptoms (LUTS) included urgency, frequency, reduced flow, hesitancy, nocturia, dribbling, incontinence and incomplete emptying of the bladder etc. present in $85.9 \%$ patients followed by lower back pain in $21.9 \%$ patients. Weight loss and fever was present in $17.2 \%$ and $12.5 \%$ patients respectively. Other symptoms like hematuria, perianal pain, pain during defecation, suprapubic pain etc. present in $18.7 \%$ patients. (Figure 1)

Out of 20 patients of prostatic carcinoma $75 \%$ patients show PSA value greater than $10 \mathrm{ng} / \mathrm{ml}$, however $13.9 \% \mathrm{BPH}$ patients also show the same. Out of 36 patients of BPH most common PSA value encountered in present study was less than $4 \mathrm{ng} / \mathrm{ml}$ followed by $4-10 \mathrm{ng} / \mathrm{ml}$ in $61.1 \%$ \& $25 \%$ patients respectively. However $15 \%$ and $10 \%$ of prostatic carcinoma patients also show PSA value less than $4 \mathrm{ng} / \mathrm{ml} \& 4-10 \mathrm{ng} / \mathrm{ml}$. (Table 2) Sensitivity for diagnosing the malignancy was $85 \%$ and specificity was to $61.5 \%$.

Most patients with benign lesions have smooth gland on DRE with $66.7 \%$ of BPH patients have smooth gland on DRE. However $25 \%$ of patients with prostatic carcinoma also show smooth prostatic gland on DRE. In present study, patients of prostatic carcinoma show nodular prostatic gland on DRE in $60 \%$ patients. While $25 \%$ patients of BPH also show nodular gland on DRE. Tender prostate on DRE found mostly in infective etiology. (Table 3) So, sensitivity for diagnosing carcinoma prostate through DRE was $75 \%$ and specificity was $72.7 \%$.

The commonest echotexture pattern found on TRUS, in prostatic carcinoma patients was hypoechoic echotexture in $70 \%$ patients followed by mixed echotexture in $20 \%$ patients. While in Benign prostatic lesion common echotexture pattern found was mixed echotexture followed by hypoechoic echotexture.(Table 4) Figure 4 shows Prostate cancer in Greyscale transverse ultrasound section of a prostate with no focal abnormalities visible while on Power Doppler of the same section shows a focal hypervascular area demonstrated to be a carcinoma on biopsy.

In present study $75 \%$ patients of prostatic CA show lesion in peripheral location on TRUS while $22.2 \%$ patients of BPH also show lesion in peripheral location. $55.6 \%$ patients of BPH show lesion involving inner gland on TRUS while $5 \%$ of prostatic carcinoma patients show involvement of inner gland. (Table 5)

Out of the 64 patients in the study $75 \%$ patients of prostatic carcinoma show interrupted \& irregular capsule and 25\% patients of prostatic carcinoma show continues \& regular capsule. Only $8.2 \%$ patients of benign lesions show interrupted \& irregular capsule, while rest of the benign lesions show continues \& regular capsule. (Table 6) Out of the 64 patients in the study $80 \%$ patients of prostatic carcinoma show increased vascularity on Color Doppler but $25 \%$ of benign lesion also show increased vascularity including all three cases of prostatitis and one out of two case of prostatic abscess. (Table 7) Figure 5 (a) shows focal echopoor lesion (arrow) with capsular invasion on axial transrectal ultrasound and 5 (b) in T2 weighted axial MRI confirms stage T3a prostate cancer with capsular invasion sparing the left seminal vesicle.

Out of 20 patients of prostatic carcinoma $50 \%$ patients had prostatic volume between $25-50 \mathrm{cc}$, followed by between $51-75$ cc in $20 \%$ of carcinoma patients. Prostatic volume less than 25 Cc and more than 75 cc found in same frequency of $15 \%$ for each range. Out of 36 patients of BPH $50 \%$ patients had prostatic volume between $25-50 \mathrm{cc}$, followed by between $51-75$ CC \& more than 75 CC in $30.5 \%$ \& $16.7 \%$ of BPH patients respectively. Prostatic volume less than $25 \mathrm{cc}$ found only in one patient of BPH.(Table 8) Sensitivity for detection of malignancy by TURS and colour Doppler was $80 \%$ and specificity was $79.6 \%$.

$27.8 \%$ of $\mathrm{BPH}$ patients and $10 \%$ of prostatic carcinoma patients show calcification on TRUS. (Table 9) In the present study local invasion of bladder base seen in 3 cases out of 20 cases of carcinoma of prostate $15.00 \%$, the seminal vesicle invasion in 2 cases out of $20(10.00 \%)$, rectal wall invasion in 1 out of 20 cases $(5.0 \%)$. Distant metastases to the other distant organs and bone present in 6 cases $(30.00 \%)$.(Table 10) In the present study, 3 cases with local invasion were having associated findings of distant metastasis to bones and liver.

\section{DISCUSSION}

Prostate-specific antigen (PSA) has been the standard screening test for prostate cancer since its approval by the FDA [6]. After its commencement it was utilize as surveillance tool for detection of prostate cancer.

In present study, PSA values ranges from $1.1 \mathrm{ng} / \mathrm{ml}$ to 226 $\mathrm{ng} / \mathrm{ml}$ with mean value $15.8 \mathrm{ng} / \mathrm{ml}$. Mean PSA value in patients with benign prostatic lesion was $5.8 \mathrm{ng} / \mathrm{ml}$ while in patients with prostatic carcinoma was $35.4 \mathrm{ng} / \mathrm{ml}$. In study done by Cho et al.[7] mean values of serum PSA in patients with prostatic carcinoma was $116.3 \mathrm{ng} / \mathrm{ml}$ and those for the benign group were $5.3 \mathrm{ng} / \mathrm{ml}$. And study done by Santos et al.[8] mean values of PSA were $7.6 \mathrm{ng} / \mathrm{ml}$ in patients with benign 
pathology at biopsy and $48.1 \mathrm{ng} / \mathrm{ml}$ in patients with positive results for prostatic cancer. The incidence of prostatic carcinoma also increases with increases in the serum level of PSA. The highest incidence of prostatic carcinoma was seen in patients whose serum PSA levels were $>20 \mathrm{ng} / \mathrm{ml}$. [9] Some investigators believe that false positive results of PSA are too high and result in unnecessary and more invasive follow-up procedures such as biopsy. Some other investigators have even suggested that, in general, screening with PSA test results in over-diagnosis of Prostatic carcinoma and, hence, over-treatment of indolent forms of prostatic CA that should not be treated due to its non-aggressive and chronic nature. [10]

In the present study, the most of the patients present with lower urinary tract symptoms $85.9 \%$ of total patients followed by lower back pain in $21.9 \%$ patients. Lower urinary tract symptoms included urgency, frequency, reduced flow, hesitancy, nocturia, dribbling, incontinence and incomplete emptying of the bladder. A substantial number of clinicians perceive that there is a link between lower urinary tract symptoms \& prostatic carcinoma and recommend screening for early cancer in men with urinary symptoms (Hoffman 2011; Belbase et al. 2013). [11, 12]

As ultrasound technology has become more refined, the use of TRUS in the evaluation of prostatic disease has increased. Transrectal ultrasound has received increasing attention recently because of its potential for early detection of prostate cancer. Transrectal ultrasound is able to detect more tumours and more early than other methods. Additionally, technical developments have occurred with the introduction of Colour Doppler that is an important adjuvant factor in the prostatic cancer investigation for increasing both positive predictive value and sensitivity.

Prostate cancer most commonly appears as a hypo echoic focal lesion in the peripheral zone on TRUS but the appearances are variable with considerable overlap with benign lesions. In present study, patients of $70 \%$ of patients with prostatic carcinoma had hypoechoic echotexture on TRUS followed by mixed echotexture in $20 \%$ patients. However similar hypoechoic lesions of the prostate were also detected other pathologies such as inflammatory changes, granulomatous prostatitis, benign prostatic hyperplastic nodules, smooth muscle bundles, fibrosis or dilated prostatic ducts or cysts. The mixed echo pattern of BPH may mask any central gland tumour as it is indistinguishable from BPH. [13]. In spite of variable appearances, the following were strongly suspicious of carcinoma: echopoor nodule in the Peripheral Zone (PZ); diffuse echopoor change in the PZ; nodule with surrounding altered echogenicity and a hypervascular echopoor nodule in the PZ [14] Classically $70 \%$ of cancers originate from the $\mathrm{PZ}, 10 \%$ from the $\mathrm{CZ}$ and $20 \%$ from the TZ. $60-70 \%$ of cancers are echopoor but only $17-57 \%$ of echopoor foci are malignant. $30-40 \%$ of cancers are isoechoic and small percentages are echogenic. [15]

The most reliable sign of prostatic carcinoma on ultrasound is the presence of capsular breach detectable either by apparent absence of capsule or some times by irregular echodense areas which appears to extend through the capsule. Distortion of symmetry of capsule is also suspicious of neoplasm. Out of the 64 patients in the study $75 \%$ patients of prostatic CA show interrupted \& irregular capsule and $25 \%$ patients of prostatic CA show continues \& regular capsule. Only $18.2 \%$ patients with benign lesions show interrupted \& irregular capsule, while rest of the benign lesions show continues \& regular capsule. In the present study, local invasion of bladder base seen in 3 out of 20 cases of prostatic carcinoma ( $15.00 \%)$, the seminal vesicle invasion in 2 out of 20 cases $(10.00 \%)$, rectal wall invasion in 1 out of 20 case $(5.0 \%)$.
Distant metastases to the other distant organs and bone were present in 6 cases $(30.00 \%)$. In the present study, 3 locally invasive cases of prostatic carcinoma were with distant metastases to bones and liver. So in case of local invasion one should always look for the metastases.

In Colour Doppler, $80 \%$ cases of prostatic carcinoma out of 20 cases show increased vascularity, but $25 \%$ cases of benign lesion out of 44 cases also show increased vascularity. It was found that one case of carcinoma of prostate which had hyperechoic echotexture on gray scale but it showed increased vascularity on Doppler, while in other case we misdiagnosed carcinoma of prostate based on hypoechoic lesion with increased vascularity but latter it proven as prostatitis on histopathology. Also, it was found that transrectal gray-scale ultrasound and colour Doppler as complimentary to each other when performed together, so we recommended that colour Doppler should be routinely performed together with transrectal gray-scale ultrasound to improve the diagnosis of prostatic lesions. The role of colour Doppler is inevitable in detecting a vascular lesion, but it loses its importance in differentiating infective/ inflammatory lesions from malignant lesions. Another study that performed Doppler TRUS staging revealed a sensitivity of $59 \%$ for detecting locally advanced disease. [16]

In present study, 25 cases were diagnosed as carcinoma of prostate based on TRUS and colour Doppler finding, on histopathological examination 16 of them confirmed as prostatic carcinoma while other 8 cases proved as BPH and one proved as prostatitis. While out of 32 cases diagnosed as BPH based on TRUS and colour Doppler, 28 cases confirmed as BPH on histopathology and other 4 proved as carcinoma of prostate. It is still believed that TRUS guided biopsy is the only accurate preoperative method for early diagnosis of prostatic carcinoma. TRUS also enables visualization of suspected lesions. [17]

Trans-rectal ultrasound demonstrated a sensitivity of $80 \%$, and a specificity of $79.6 \%$. These values are within the range reported by several studies where values for sensitivity ranged from $41 \%$ to $96 \%$, for specificity, from $27 \%$ to $81 \%$. [ $18,19,20]$

Sensitivity and specificity of DRE was $75 \%$ and $72.2 \%$ respectively while, Sensitivity and specificity of PSA was $75 \%$ and $72.2 \%$ respectively. PSA was the single most non-invasive test with highest sensitivity in our study, while its specificity also lowest $61.5 \%$ among the TRUS, DRE and PSA, if we increase cut-off normal value of PSA then its specificity increases but at the expense of its sensitivity. DRE test is based on the clinical fact that the cancerous tissue is stiffer than normal prostate tissue.

So, by this study, it was found that a combination of all three diagnostic method abnormalities had significantly higher Predictive Positive Value for the detection of carcinoma than any other combinations. Our study results support the suggestion that patients with abnormal findings for all three diagnostic methods should undergo the TRUS-guided biopsy of prostate.

\section{CONCLUSION}

Any single test alone is not helpful in arriving at a diagnosis, but all the three tests together give very confirmatory result, specifically to differentiate benign from malignant condition of prostate. Considering that the initial screening of patients is performed with basis on PSA levels and digital rectal examination, the trans-rectal ultrasound should play the role of trying to reduce the number of negative biopsies (unnecessary), without impairing the cancer detection capacity. 
Tables and Figures:

Table 1: Correlation between prostatic pathology and patients age

\begin{tabular}{|c|c|c|c|c|c|c|c|c|}
\hline \multicolumn{2}{|l|}{ PATHOLOGY } & $<40$ & $40-50$ & $51-60$ & $61-70$ & $71-80$ & $>80$ & Total \\
\hline \multirow[t]{2}{*}{ BPH } & $\mathbf{n}$ & 0 & 01 & 09 & 19 & 07 & 0 & \multirow[t]{2}{*}{36} \\
\hline & $\%$ & 0 & 2.8 & 25 & 52.8 & \begin{tabular}{|l|}
19.4 \\
\end{tabular} & 0 & \\
\hline \multirow{2}{*}{\begin{tabular}{|l|} 
PROSTATIC \\
CARCINOMA
\end{tabular}} & $\mathbf{n}$ & 0 & 0 & 01 & 05 & 12 & 02 & \multirow[t]{2}{*}{20} \\
\hline & $\%$ & 0 & 0 & 5 & 25 & 60 & 10 & \\
\hline \multirow[t]{2}{*}{ PROSTATITIS } & $\mathrm{n}$ & 01 & 01 & 01 & 0 & 0 & 0 & \multirow[t]{2}{*}{3} \\
\hline & $\%$ & 33.3 & 33.3 & 33.3 & 0 & 0 & 0 & \\
\hline \multirow[t]{2}{*}{ ABSCESS } & $\mathrm{n}$ & 01 & 01 & 0 & 0 & 0 & 0 & \multirow[t]{2}{*}{2} \\
\hline & $\%$ & 50 & 50 & 0 & 0 & 0 & 0 & \\
\hline \multirow[t]{2}{*}{ CALCULUS } & $\mathrm{n}$ & 0 & 0 & 01 & 01 & 0 & 0 & \multirow[t]{2}{*}{2} \\
\hline & $\%$ & 0 & 0 & 50 & 50 & 0 & 0 & \\
\hline \multirow{2}{*}{$\begin{array}{l}\text { PROSTATIC } \\
\text { CYST }\end{array}$} & $\mathrm{n}$ & 0 & 01 & 0 & 0 & 0 & 0 & \\
\hline & $\%$ & 0 & 100 & 0 & 0 & 0 & 0 & \\
\hline Total & & 02 & 04 & 12 & 25 & 19 & 02 & 64 \\
\hline
\end{tabular}

*Percentage indicate \% of patient of particular pathology fall in particular age group.

Table 2: Correlation between prostatic pathology and PSA value

\begin{tabular}{|l|l|l|l|l|l|}
\hline \multicolumn{2}{|l|}{ PATHOLOGY } & $\begin{array}{l}<\text { 4ng/ } \\
\mathrm{ml}\end{array}$ & $\begin{array}{l}4-10 \mathrm{ng} / \\
\mathrm{ml}\end{array}$ & $\begin{array}{l}\mathbf{1 0 - 2 0 n g} \\
\mathrm{ml}\end{array}$ & $\begin{array}{l}>\text { 20ng/ } \\
\mathrm{ml}\end{array}$ \\
\hline \multirow{2}{*}{ BPH } & $\mathbf{n}$ & 22 & 09 & 03 & 02 \\
\cline { 2 - 6 } & $\%$ & 61.1 & 25 & 8.3 & 5.6 \\
\hline PROSTATIC & $\mathrm{n}$ & 03 & 02 & 06 & 09 \\
\cline { 2 - 6 } CARCINOMA & $\%$ & 15 & 10 & 30 & 45 \\
\hline PROSTATITIS & $\mathbf{n}$ & 02 & 01 & 0 & 0 \\
\cline { 2 - 6 } & $\%$ & 66.7 & 33.3 & 0 & 0 \\
\hline Total & & 27 & 12 & 09 & 11 \\
\hline
\end{tabular}

${ }^{*}$ Percentage indicate $\%$ of patient of particular pathology fall in particular PSA value.

Table 3: Correlation between Digital Rectal Examination (DRE) and pathology

\begin{tabular}{|c|c|c|c|c|c|}
\hline \multicolumn{2}{|l|}{ DRE } & \multirow{2}{*}{\begin{tabular}{|l|} 
SMOOTH \\
24 \\
\end{tabular}} & \multirow{2}{*}{\begin{tabular}{|l|} 
NODULAR \\
09 \\
\end{tabular}} & \multirow{2}{*}{\begin{tabular}{|l|} 
HARD \& \\
IRREGULAR \\
03
\end{tabular}} & $\begin{array}{l}\text { TEN- } \\
\text { DER }\end{array}$ \\
\hline \multirow[t]{2}{*}{ BPH } & $\mathrm{n}$ & & & & 0 \\
\hline & $\%$ & \begin{tabular}{|l|}
66.7 \\
\end{tabular} & 25 & 8.3 & 0 \\
\hline \multirow{2}{*}{\begin{tabular}{|l|} 
PROSTĀTIC \\
CARCINOMA
\end{tabular}} & $\mathrm{n}$ & 05 & 12 & 03 & 0 \\
\hline & $\%$ & 25 & 60 & 15 & 0 \\
\hline \multirow[t]{2}{*}{ PROSTAITIS } & $\mathrm{n}$ & 01 & 0 & 0 & 02 \\
\hline & $\%$ & 33.3 & 0 & 0 & 66.7 \\
\hline \multirow[t]{2}{*}{ ABSCESS } & $\mathrm{n}$ & 0 & 0 & 0 & 02 \\
\hline & $\%$ & 0 & 0 & 0 & 100 \\
\hline \multirow[t]{2}{*}{ CALCULUS } & n & 01 & 0 & 0 & 01 \\
\hline & $\%$ & 50 & 0 & 0 & 50 \\
\hline \multirow{2}{*}{\begin{tabular}{|l} 
PROSTATIC \\
CYST
\end{tabular}} & $\mathrm{n}$ & 01 & 0 & 0 & 0 \\
\hline & $\%$ & 100 & 0 & 0 & 0 \\
\hline Total & & 32 & 21 & 06 & 05 \\
\hline
\end{tabular}

*Percentage indicate \% of patient of particular pathology showing particular DRE finding.

Table 4: Correlation between pathology and echotexture of lesion though TURS

\begin{tabular}{|c|c|c|c|c|c|c|}
\hline \multirow{2}{*}{\multicolumn{2}{|c|}{ PATHOLOGY }} & \multirow{3}{*}{\begin{tabular}{|l|l} 
HYPOE \\
CHOIC \\
08 \\
\end{tabular}} & \multirow{3}{*}{$\begin{array}{l}\text { HYPERE } \\
\text { CHOIC } \\
06 \\
\end{array}$} & \multirow{3}{*}{\begin{tabular}{|l|} 
MIX \\
ED \\
15 \\
\end{tabular}} & \multirow{3}{*}{\begin{tabular}{|l} 
ISOEC \\
HOIC \\
07 \\
\end{tabular}} & \multirow{3}{*}{\begin{tabular}{|l} 
CYSTIC TO \\
ANECHOIC \\
0 \\
\end{tabular}} \\
\hline & & & & & & \\
\hline BPH & n & & & & & \\
\hline & $\%$ & 22.2 & 16.7 & 41.7 & 19.4 & 0 \\
\hline \multirow{2}{*}{$\begin{array}{l}\text { PROSTATIC } \\
\text { CARCINOMA }\end{array}$} & $\mathrm{n}$ & 14 & 01 & 04 & 01 & 0 \\
\hline & $\%$ & 70 & 05 & 20 & 05 & 0 \\
\hline \multirow[t]{2}{*}{ PROSTATTITIS } & $n$ & 02 & 0 & 01 & 0 & 0 \\
\hline & $\%$ & 66.7 & 0 & 33.3 & 0 & 0 \\
\hline \multirow[t]{2}{*}{ ABSCESS } & $\mathrm{n}$ & 01 & 0 & 0 & 0 & 01 \\
\hline & $\%$ & 50 & 0 & 0 & 0 & 50 \\
\hline \multirow[t]{2}{*}{ CAILCULUS } & $\mathrm{n}$ & 01 & 0 & 0 & 01 & 0 \\
\hline & $\%$ & 50 & 0 & 0 & 50 & 0 \\
\hline
\end{tabular}

\begin{tabular}{|l|l|l|l|l|l|l|}
\hline PROSTATIC & $\mathbf{N}$ & 0 & 0 & 0 & 0 & 01 \\
\cline { 2 - 7 } & $\%$ & 0 & 0 & 0 & 0 & 100 \\
\hline
\end{tabular}

\begin{tabular}{l|l|l|l|l|l|l|l|} 
CYST & $\%$ & 0 & 0 & 0 & 0 & 100
\end{tabular}

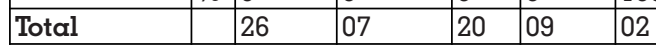

*Percentage indicate \% of patient of particular pathology showing particular echotexture on TRUS.

Table 5: Correlation between pathology and location of lesion

\begin{tabular}{|c|c|c|c|c|}
\hline \multicolumn{2}{|l|}{ PATHOLOGY } & \multirow{2}{*}{\begin{tabular}{|l} 
PERIPHERAL \\
08 \\
\end{tabular}} & \multirow{2}{*}{\begin{tabular}{|l|} 
INNER \\
20 \\
\end{tabular}} & \multirow{2}{*}{\begin{tabular}{|l}
$\begin{array}{l}\text { PERIPHERAL } \\
\text { +INNER }\end{array}$ \\
08 \\
\end{tabular}} \\
\hline$\overline{B P H}$ & $\mathbf{n}$ & & & \\
\hline & $\%$ & 22.2 & 55.6 & 22.2 \\
\hline \multirow{2}{*}{$\begin{array}{l}\text { PROSTATIC } \\
\text { CARCINOMA }\end{array}$} & $\mathbf{n}$ & 15 & 01 & 04 \\
\hline & $\%$ & 75 & 05 & 20 \\
\hline \multirow[t]{2}{*}{ PROSTATITIS } & $\mathbf{n}$ & 01 & 0 & 02 \\
\hline & $\%$ & 33.3 & 0 & 66.7 \\
\hline \multirow{2}{*}{\begin{tabular}{|l|} 
PROSTATIC \\
ABSCESS
\end{tabular}} & $\mathrm{n}$ & 02 & 0 & 0 \\
\hline & $\%$ & 100 & 0 & 0 \\
\hline \multirow{2}{*}{$\begin{array}{l}\text { PROSTATIC } \\
\text { CALCULUS }\end{array}$} & $\mathrm{n}$ & 0 & 02 & 0 \\
\hline & $\%$ & 0 & 100 & 0 \\
\hline \multirow{3}{*}{\begin{tabular}{|l} 
PROSTATIC \\
CYST
\end{tabular}} & $\mathrm{n}$ & 0 & 01 & 0 \\
\hline & $\%$ & 0 & 100 & 0 \\
\hline & & 26 & 24 & 14 \\
\hline
\end{tabular}

*Percentage indicate \% of patient of particular pathology found in particular location on TRUS.

Table 6: Correlation between prostatic pathology and capsular status

\begin{tabular}{|c|c|c|c|}
\hline \multicolumn{2}{|l|}{ PATHOLOGY } & \multirow{2}{*}{\begin{tabular}{|l} 
CONTINUES AND \\
REGULAR \\
29
\end{tabular}} & \multirow{2}{*}{\begin{tabular}{|l|} 
INTERRUPTED \\
AND IRREGULAR \\
07
\end{tabular}} \\
\hline BPH & $\mathrm{n}$ & & \\
\hline & $\%$ & 80.6 & 19.4 \\
\hline \multirow{2}{*}{$\begin{array}{l}\text { PROSTATIC } \\
\text { CARCINOMA }\end{array}$} & $\mathrm{n}$ & 05 & 15 \\
\hline & $\%$ & 25 & 75 \\
\hline \multirow[t]{2}{*}{ PROSTATTITIS } & $\mathrm{n}$ & 02 & 01 \\
\hline & $\%$ & 66.7 & 33.3 \\
\hline \multirow{2}{*}{$\begin{array}{l}\text { PROSTATIC } \\
\text { ABSCESS }\end{array}$} & $\mathrm{n}$ & 02 & 0 \\
\hline & $\%$ & 100 & 0 \\
\hline \multirow{2}{*}{$\begin{array}{l}\text { PROSTATIC } \\
\text { CALCULUS }\end{array}$} & $\mathrm{n}$ & 02 & 0 \\
\hline & $\%$ & 100 & 0 \\
\hline \multirow{3}{*}{$\begin{array}{l}\text { PROSTATIC } \\
\text { CYST }\end{array}$} & $\mathrm{n}$ & 01 & 0 \\
\hline & $\%$ & 100 & 0 \\
\hline & & 41 & 23 \\
\hline
\end{tabular}

*Percentage indicate \% of patient of particular pathology showing particular capsular status on TRUS.

Table 7: Correlation between prostatic pathology and vascularity on colour doppler ultrasound

\begin{tabular}{|l|l|l|l|}
\hline \multicolumn{2}{|l|}{ PATHOLOGY } & $\begin{array}{l}\text { NORMAL } \\
\text { VASCULARITY }\end{array}$ & $\begin{array}{l}\text { INCREASED } \\
\text { VASCULARITY }\end{array}$ \\
\hline \multirow{2}{*}{ BPH } & $\mathbf{n}$ & 29 & 07 \\
\cline { 2 - 4 } & $\%$ & 80.6 & 19.4 \\
\hline PROSTATIC & $\mathbf{n}$ & 04 & 16 \\
\cline { 2 - 4 } CARCINOMA & $\%$ & 20 & 80 \\
\hline \multirow{2}{*}{ PROSTATITIS } & $\mathbf{n}$ & 00 & 03 \\
\cline { 2 - 4 } & $\%$ & 0 & 100 \\
\hline $\begin{array}{l}\text { PROSTATIC } \\
\text { ABSCESS }\end{array}$ & $\mathbf{n}$ & 01 & 01 \\
\cline { 2 - 4 } $\begin{array}{l}\text { PROSTATIC } \\
\text { CALCULUS }\end{array}$ & $\mathbf{n}$ & 02 & 50 \\
\cline { 2 - 4 } $\begin{array}{l}\text { PROSTATIC } \\
\text { CYST }\end{array}$ & $\mathbf{n}$ & 100 & 00 \\
\cline { 2 - 4 } & $\%$ & 100 & 0 \\
\hline & & 37 & 00 \\
\hline
\end{tabular}

*Percentage indicate \% of patient of particular pathology showing increased or decreased vascularity on TRUS.

Table 8: Correlation between pathology and prostatic volume 


\begin{tabular}{|c|c|c|c|c|c|}
\hline \multicolumn{2}{|l|}{ PATHOLOGY } & \multicolumn{3}{|c|}{\begin{tabular}{|l|l|l|l|}
$<25$ CC & $25-50$ CC $51-75$ CC
\end{tabular}} & \multirow{2}{*}{\begin{tabular}{|l}
$>75 \mathrm{CC}$ \\
06
\end{tabular}} \\
\hline \multirow[t]{2}{*}{ BPH (\%) } & $\mathbf{n}$ & 01 & 18 & 11 & \\
\hline & $\%$ & 2.8 & 50 & 30.5 & 16.7 \\
\hline \multirow{2}{*}{\begin{tabular}{|l} 
PROSTATIC \\
CARCINOMA (\%)
\end{tabular}} & $\mathrm{n}$ & 03 & 10 & 04 & 03 \\
\hline & $\%$ & 15 & 50 & 20 & 15 \\
\hline \multirow{2}{*}{\begin{tabular}{|l|} 
PROSTATITIS \& \\
ABSCESS (\%) \\
\end{tabular}} & $\mathrm{n}$ & 02 & 03 & 0 & 0 \\
\hline & $\%$ & 40 & 60 & 0 & 0 \\
\hline \multirow{3}{*}{\begin{tabular}{|l} 
PROSTATIC \\
CALCULUS \& \\
CYST (\%) \\
\end{tabular}} & $\mathrm{n}$ & 01 & 02 & 0 & 0 \\
\hline & $\%$ & |33.3 & 66.7 & 0 & 0 \\
\hline & & 07 & 33 & 15 & 09 \\
\hline
\end{tabular}

*Percentage indicate \% of patient of particular pathology who had particular prostatic volume range on TRUS

Table 9: Distribution of patients according to calcification on TURS

\begin{tabular}{|l|l|l|}
\hline NO. & CALCIFICATION & $\begin{array}{l}\% \text { OF } \\
\text { PATIENTS }\end{array}$ \\
\hline BPH & 10 (OUT OF 36) & 27.8 \\
\hline PROSTATIC CARCINOMA & O2 (OUT OF 20) & 10 \\
\hline
\end{tabular}

Table 10: Distribution of prostatic carcinoma patients according to local invasion and distant metastases

\begin{tabular}{|l|l|l|}
\hline LOCAL INVASION & NO. OF PATIENTS & $\%$ OF PATIENTS \\
\hline BLADDER & 3 & 15 \\
\hline SEMINAL VESICLE & 2 & 10 \\
\hline RECTUM & 1 & 5 \\
\hline DISTANT METASTASES & 6 & 30 \\
\hline
\end{tabular}

Figure 1: Distribution of patients according to symptoms

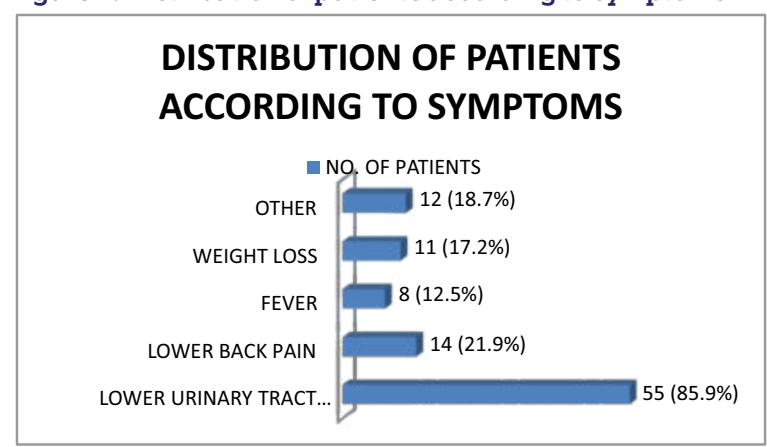

Figure 2: Illustration of prostatic biopsy needle in the parenchyma

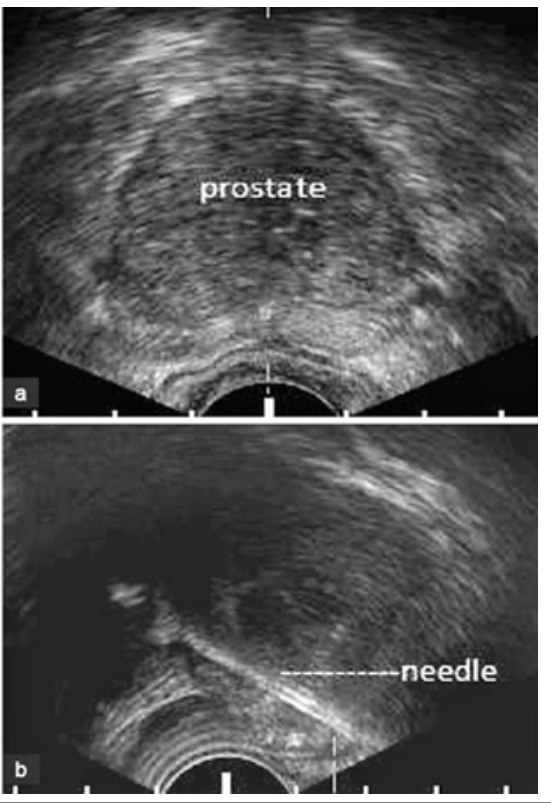

Figure 3: Illustrates echogenic track post biopsy

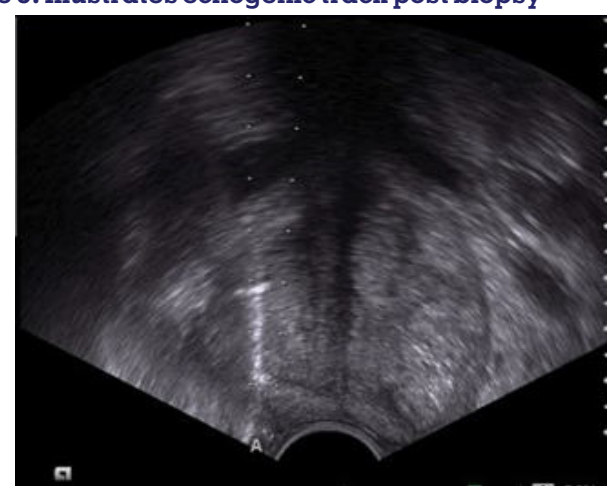

Figure 4: Prostate cancer. Greyscale transverse ultrasound section of a prostate with no focal abnormalities visible. Power Doppler (unenhanced) of the same section shows a focal hypervascular area (arrow) demonstrated to be a carcinoma on biopsy.

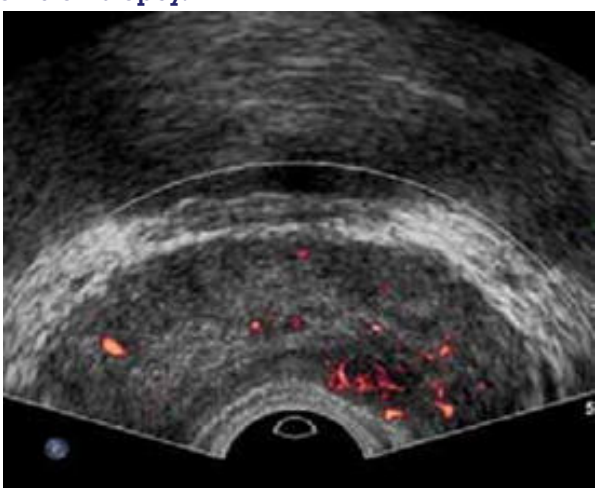

Figure 5: A prostate cancer is seen as a focal echopoor lesion (arrow) with capsular invasion on axial transrectal ultrasound (a). T2 weighted axial MRI (b) confirms stage T3a with capsular invasion sparing the left seminal vesicle (arrow).

a)

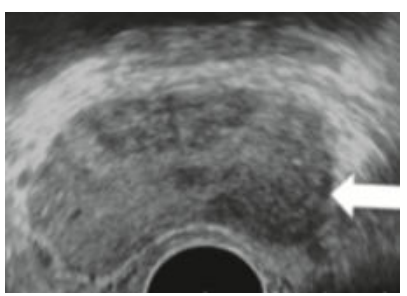

b

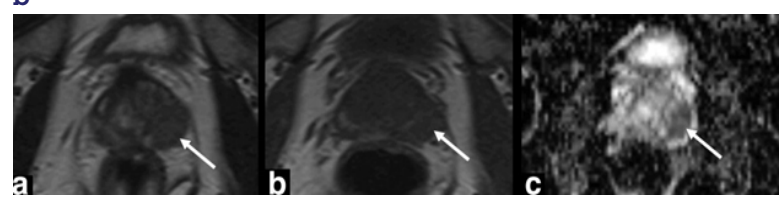

\section{REFERENCES}

1. Ogwuche E; Hameed M, Animashaun, E. Urological Transabdominopelvic Ultrasound Findings In Patients With Prostatic Diseases. The Internet Journal of Urology. Volume 11, No 2.

2. Nickel JC. Inflammatory conditions of the male genitourinary tract: prostatitis and related conditions, orchitis, and epididymitis. In: Wein AJ, Ed. CampbellWalsh Urology. 9thEd. Philadelphia, Pa: Saunders Elsevier; 2007: chap 9.

3. Praveenkumar $P$ and Chanabasappa Chavadi Role of Transrectal ultrasonography and per rectal examination / International Journal of Biomedical Research 2015; 6(03): 185-188.

4. Durkan GC, Greene DR. Diagnostic dilemmas in ditection of prostate cancer in patients undergoing transrectal ultrasound guided needle biopsy of the prostate. Prostate Cancer Prostatic Dis 2000;3:13-20.

5. Shim HB, Lee SE, Park HK, Ku JH. Significance of suspicious lesions at transrectal ultrasonography in men with serum prostate-specific antigen levels of $<20 \mathrm{ng} / \mathrm{ml}$. Tumori 2007;93:178-181

6. National Cancer Institute: Prostate Specific Antigen (PSA) Test. (2012) Accessed: June 20, 2016: http://www.cancer.gov/types/prostate/psa-fact- 
sheet.

7. Jeong Yeon Cho, MD, Seung Hyup Kim, MD, Sang Eun Lee, MD. diffuse prostatic lesions: role of color doppler and power doppler ultrasonography. J Ultrasound Med 17:283-287, 1998.

8. Viviane Cristine Tavares Santos, Miguel Angelo Milito, Edson Marchiori. Current role of transrectal ultrasonography in the early detection of prostatic cancer. Radio Bras vol.39 Sao Paulo May/June 2006.

9. Barakzi MA, Mubarak M, Kazi JI (2011). Histopathological lesions in transrectal ultrasound guided biopsies of prostate with raised serum prostate specific antigen. Nephro Urol, 3, 186-90.

10. 94.Zappa M (1998). Over-diagnosis of prostate carcinoma by screening: An estimate based on the results of the Florence Screening Pilot Study. Ann Oncol, 9, 1297-300.

11. Hoffman R (2011). Screening for prostate cancer. N Engl J Med, 365, 2013-19.

12. Belbase NP, Agrawal CS, Pokharel PK, et al (2013). Prostate cancer screening in a healthy population cohort in Eastern Nepal: an explanatory trial study. Asian Pac J Cancer Prev, 14, 2835-8.

13. Purohit R, Shinohara K, Meng M, Carroll PR. Imaging clinically localized prostate cancer. Urol Clin North Am 2003;30:279-93.

14. Patel U, Rickards D. Handbook of transrectal ultrasound and biopsy of the prostate. London, UK: Martin Dunitz; 2002 ....////103.Loch T. Urologic imaging for localised prostate cancer in 2007. World J Urol 2007;25:121-9.

15. Loch T. Urologic imaging for localised prostate cancer in 2007. World J Urol 2007:25:121-9.

16. Sauvain JL, Palascak P, Bourscheid D, et al. Value of power Doppler and 3D vascular sonography as a method for diagnosis and staging of prostate cancer. Eur Urol 2003; 44:21_30; discussion 30_1.

17. Loch T, Eppelmann U, Lehmann J, Wullich B, Loch A, Stöckle M. Transrectal ultrasound guided biopsy of the prostate: Random sextant versus biopsies of sono morophologically suspicious lesions. World J Urol 2004;22:357 60.

18. Kuligowska E, Barish MA, Fenlon HM, Blake M. Predictors of prostate carcinoma: accuracy of gray scale and color Doppler US and serum markers. Radiology 2001;220:757-764.

19. Kelly IMG, Lees WR, Rickards D. Prostate cancer and the role of color Doppler US. Radiology 1993; 189:153-156.

20. Rubens DJ, Gottlieb RH, Maldonado Jr CE, Frank IN. Clinical evaluation of prostate biopsy parameters: gland volume and elevated prostate-specific antigen level. Radiology 1996;199:159-163.

21. Prostate cancer vs. post-biopsy hemorrhage: Diagnosis with T2* and diffusion'weighted imaging. Journal of MRI 31:1387-1394 (2010). 